\title{
ГЕОЛОГИЯ
}

\section{Модификация уравнения Арчи для определения водонасыщенности нефтяного месторождения Восточный Багдад}

\section{АЛЬ-ОБЕЙДИ СУДАД ХАМИД}

Практическая ценность этой работы заключается в повышении эффективности разведки нефтяных и газовых месторождений в Восточном Багдаде за счет оптимизации и сокращения комплекса каротажа скважин, отбора керна, отбора проб и испытаний пластов пластов и компьютеризации данных интерпретации для обеспечения необходимого точность и надежность определения петрофизических параметров, которые позволят уточнить и увеличить доказанные запасы месторождений углеводородов в Восточном Багдаде. Для расчета наиболее точных значений водонасыщенности для каждого интервала Зубаирской пласты была разработана конкретная модифицированная форма уравнения Арчи, соответствующая этой формации.

Ключевые слова: Арчи, Пористость, Каротаж, Водонасыщенность.

\section{Введение}

Эффективность разведки нефтяных и газовых месторождений во многом определяется уровнем и объемом сейсмических работ, методами и приемами каротажа скважин. Решение задачи, безусловно, основано на данных ГИС для выделения несущих зон и определения их параметров, которые затем используются для подсчета запасов нефти и газа. Для характеристики водонасыщенности пород-коллекторов используется коэффициент водонасыщенности $(\mathrm{Sw})$. Водонасыщенность пласта определяется как отношение объема пор, заполненных водой, к общему объему порового пространства. Для определения $\mathrm{Sw}$ необходимо знать многие другие петрофизические параметры, которые могут быть получены при каротажном исследовании ствола скважины или лабораторными измерениями керна. Наиболее распространенным из методов, используемых для определения $\mathrm{Sw}$, является знаменитая формула Арчи:

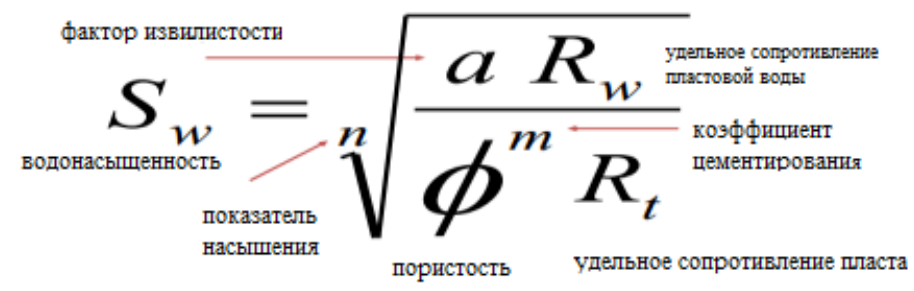

Для чистых зернистых песчаников общепринятые значения следующие: $\mathrm{n}=\mathrm{m}=2$, a $=1$ и (1) становится; 
$S_{w}=\sqrt{\frac{R_{w}}{\varnothing R_{t}}}$

\section{Методология}

Поскольку формула Арчи в этой форме дает хорошие результаты только в Чистых терригенных пластах [ 1,2 ], в данной работе предлагается модифицированная форма формулы Арчи, в которой использовались конкретные значения «т» и «а». Эта модифицированная форма позволяет использовать формулу Арчи как в чистых, так и в глинистых пластах, особенно для месторождений Восточного Багдада. Как видно из уравнения Арчи, важным для точного определения насыщения является определение коэффициента пористости (ф) [3].

\section{Пористость Пласта}

Пористость различных интервалов Зубаирской пласты (Восточно-багдадское месторождение, территория Ирака) рассчитывалась по нескольким методикам с целью выбора наиболее точного значения пористости, которое используется при определении насыщенности коллектора. В связи со значительным влиянием пористости на расчет водонасыщенности (Sw) были рассмотрены следующие методы определения пористости [ 4 ]:

- Метод нейтронного каротажа (НГК);

- Метод регистрации плотности (ГГК-П);

- Метод построения кросс-плотов на комплексе (НГК)- (ГГК-П);

- Акустический (акустический каротаж) метод, использующий среднее время

уравнение (АК).

В качестве эталонных значений пористости (для корректировки результатов интерпретации этих методов) использовались значения пористости, определенные по керну. В результате сравнения значений пористости, полученных в соответствии с комплексом этих методов, и измеренных значений пористости пласта из анализа керна, было обнаружено, что наиболее приемлемыми параметрами корреляции по сравнению с другими используемыми методами является интегрированный метод построения кросс- плот (с использованием метод треугольника, см. Таблицу1). Наиболее предпочтительным в задаче определения пористости пласта является использование метода треугольника, поскольку, согласно статистическому анализу, коэффициент корреляции для этого метода самый высокий, а погрешность в процентах - самая низкая. Эти рассчитанные значения пористости затем используются при определении водонасыщенности с использованием уравнения Арчи. 
Таблица 1: Параметры корреляции для метода НГК, ГГК-П и АК как индивидуальных индикаторов, так и комбинационных индикаторов при определении пористости пласта.

\begin{tabular}{|c|c|c|c|c|}
\hline Метод & $\begin{array}{l}\text { Средняя процентная } \\
\text { ошибка, \% }\end{array}$ & $\begin{array}{l}\text { Абсолютная средняя } \\
\text { ошибка,\% }\end{array}$ & $\begin{array}{l}\text { Ошибка стандартного } \\
\text { отклонения \% } \%\end{array}$ & $\begin{array}{l}\text { Коэффициент } \\
\text { корреляции }\end{array}$ \\
\hline НГК & +1.699 & 4.870 & 6.853 & 0.906 \\
\hline ГГК-П & +1.262 & 5.648 & 7,4931 & 0.883 \\
\hline $\begin{array}{l}\text { НГК, ГГК-П } \\
\text { метод кросс-плот (с } \\
\text { исплььованием метод } \\
\text { треугольника) }\end{array}$ & +2.276 & 4.591 & 6.244 & 0.923 \\
\hline $\begin{array}{l}\text { НГК, ГГК-П } \\
\text { кросс- плот (использование } \\
\text { cтандартныхх днаграммя) }\end{array}$ & +13.096 & 13.096 & 14.739 & 0.884 \\
\hline $\mathrm{AK}$ & -11.555 & 11.576 & 12.511 & 0.922 \\
\hline
\end{tabular}

Сравнение значений пористости пласта, рассчитанных разными методами каротажа, с измеренными значениями пористости представлено графически на рис.3. Этот Рис. Подтверждает результат Таблицы 1. Он показывает, что наиболее точные значения пористости пласта рассчитаны методом кросс-плотов ((методом треугольника).

\section{Факторы Цеменции И Изивочности}

Основные значения степени цементации $\mathrm{m}$ и коэффициента извилистости а (постоянной, зависящей от состояния горных пород) принимают следующие значения: $\mathrm{m}=2,0$ и а $=1,0$.

Эти значения широко используются в различных исследованиях как наиболее типичные значения этих параметров. Однако, как отмечают многие авторы, значения этих параметров могут различаться для разных типов залежей и существенно влиять на определение насыщенности пластов, особенно при интерпретации данных ГИС с использованием таких методов, как метод, основанный на использовании уравнений Арчи [ 5 ].
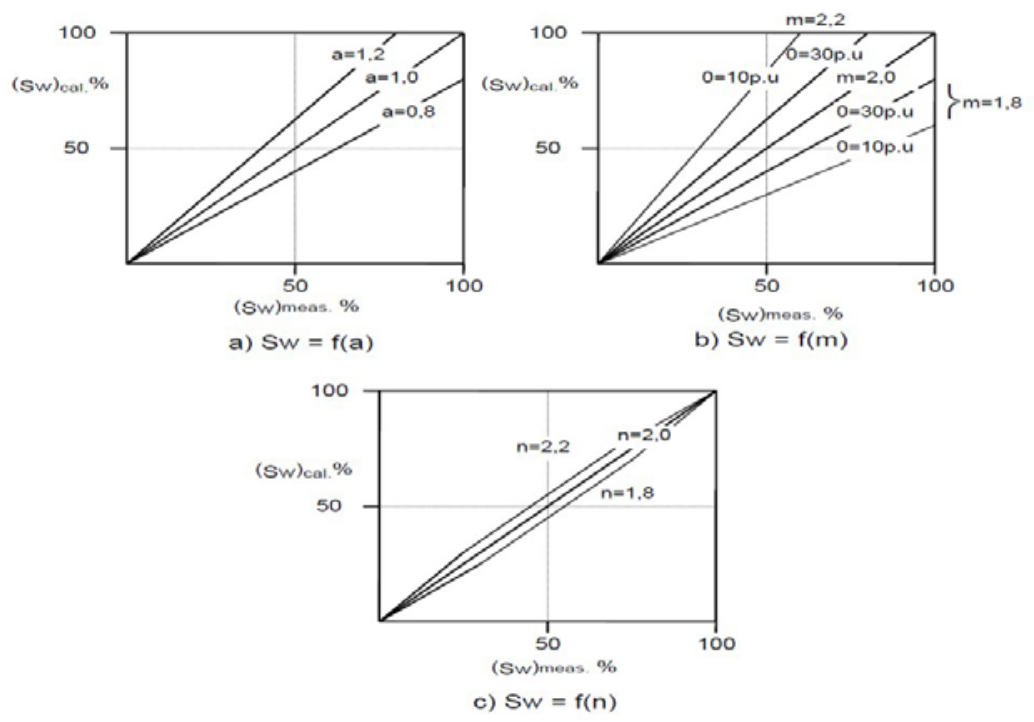

Рис. 1: Влияние m, а и n на расчетные значения водонасыщенности, $(\mathrm{Sw})$ кал. (где $\mathrm{Sw}_{\text {meas }}$ водонасыщенность, измеренная лабораторно). 
Установлено, что параметр м оказывает большее влияние на расчет коэффициента водонасыщенности, чем параметр а, как видно из Рис. 1. Таким образом, коэффициент цементации $\mathrm{m}$ следует рассматривать как более информативный параметр [6]. Теоретическую основу применяемого метода можно легко установить при логарифмическом представлении уравнения Арчи, когда классическое значение, принятое для n, равно 2.

$$
\log R_{t}=-m \log \emptyset+\log a R_{w}-2 \log S_{w}
$$

Описанный выше метод обеспечивает графическое определение значений удельного сопротивления пластовой воды Rw и коэффициента водонасыщения Sw. Для определения $\mathrm{Rw}$, как видно из уравнения 3, при значении $\mathrm{Sw}=100 \%$ (в водоносных зонах при 100\% - ном водонасыщении) существует линейная зависимость между удельным сопротивлением и пористостью следующим образом:

$$
\log R_{t}=-m \log \emptyset+\log R_{w}
$$

Линия, определяемая этим уравнением, должна проходить через нижние точки удельного сопротивления на логарифмической диаграмме $(\log \mathrm{Rt})$ и $(\log \varphi)$ для водоносных зон. Эта линия представляется наиболее точной для всего диапазона значений. Наклон этой прямой численно равен $\mathrm{m}$, Как видно из уравнения 4, а ее пересечение с осью $\phi=$ 100\% определяет значения Rw и следующим образом:

$\log ($ intersection point $)-\log \left(\mathrm{a}_{\mathrm{t}}\right)$

Для определения конкретных значений m и а, характерных для пласта Зубайр, было использовано значение $\mathrm{Rw}=0,018$ Ом-м. Это значение было рассчитано по кажущемуся удельному сопротивлению по данным каротажа скважин и результатам лабораторных измерений. Для наиболее точных значений водонасыщенности для каждого интервала Зубаирской пласти, основанных на модифицированной форме уравнения Арчи, как показано на Рис.2, были получены следующие значения $\mathrm{m}=1,917$ и а $=0,583$.

\section{Специфическое Модифицированное Уравнение Арчи}

Подстановка значений $\mathrm{m}=1,917$ и а $=0,583$ в уравнение 3 приводит к следующему виду уравнения Арчи:

$$
\begin{aligned}
& \log R_{t}=-1.917 \log \emptyset+\log R_{w}-2 \log S_{w}+\log 0,583 \\
& S_{w}=\sqrt{\frac{0.010}{\emptyset_{t r}^{1.917} R_{t}}}
\end{aligned}
$$

Где: $\emptyset_{\mathrm{tr}}$ пористость, полученная методом треугольника [7]. 


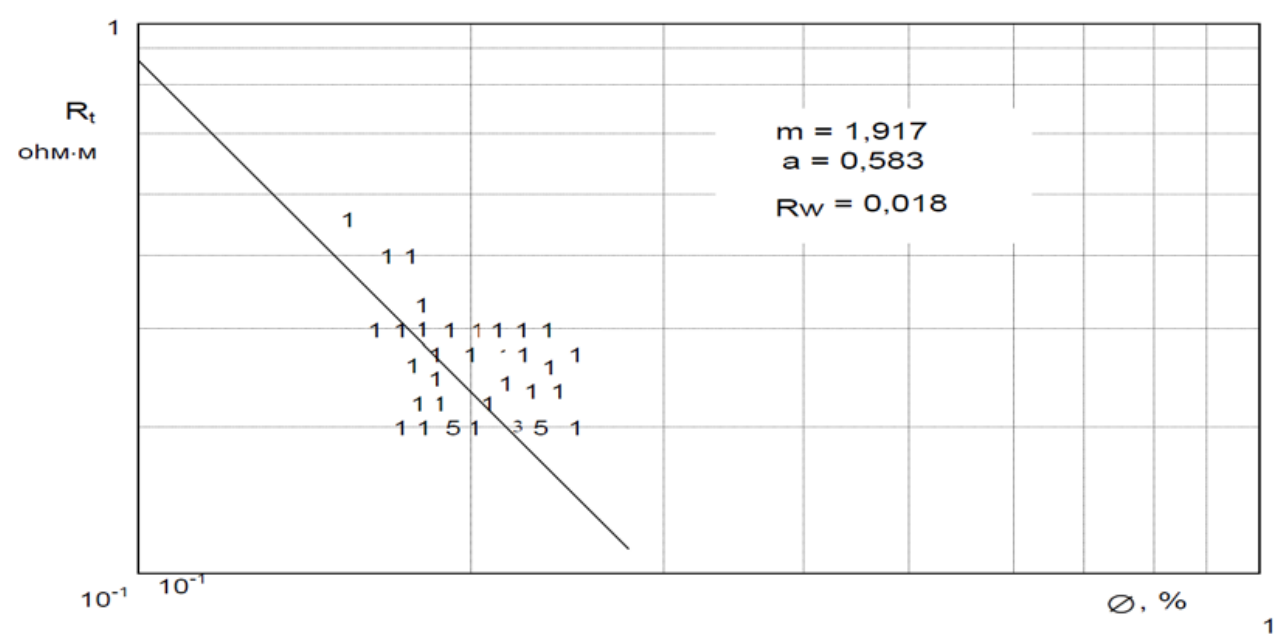

Рис. 2. Зависимость Rt от $\varphi$

Table 2 : Значения Sw, полученные по модифицированным и стандартным уравнениям Арчи и по результатам лабораторных измерений для ряда выбранных интервалов залежи зубаир.

\begin{tabular}{|c|c|c|c|c|c|c|}
\hline Номер скважины & Глубина, м & $\begin{array}{c}\text { Rt } \\
\text { OM.M }\end{array}$ & $\varnothing_{\mathrm{tr}}$ & \begin{tabular}{|c|}
\multicolumn{1}{c|}{$\mathrm{S}_{\mathrm{w}} \%$} \\
Модифцированная \\
формула Арчи
\end{tabular} & \begin{tabular}{l}
\multicolumn{1}{c}{$\mathrm{Sw} \%$} \\
Стандартная \\
формула Арчи
\end{tabular} & $\begin{array}{c}\text { Sw\%, } \\
\text { рассчитанный }\end{array}$ \\
\hline EB-55 & $\begin{array}{l}3400 \\
3457 \\
\end{array}$ & $\begin{array}{l}20 \\
20 \\
\end{array}$ & $\begin{array}{l}13.0 \\
16.3 \\
\end{array}$ & \begin{tabular}{|l|}
16.1 \\
13.0 \\
\end{tabular} & $\begin{array}{c}23 \\
18.4 \\
\end{array}$ & $\begin{array}{c}15-7 \\
14 \\
\end{array}$ \\
\hline EB-79 & $\begin{array}{l}3030 \\
3070\end{array}$ & $\begin{array}{l}30 \\
17\end{array}$ & $\begin{array}{r}6.0 \\
10.5\end{array}$ & $\begin{array}{l}27.7 \\
21.5\end{array}$ & $\begin{array}{l}40.8 \\
30.9\end{array}$ & $\begin{array}{l}26-1 \\
20-9\end{array}$ \\
\hline EB-77 & 3135 & 30 & 5.5 & 30.1 & 44.5 & $32-4$ \\
\hline EB-55 & $\begin{array}{l}3007 \\
3150\end{array}$ & $\begin{array}{c}5.5 \\
6\end{array}$ & $\begin{array}{l}16.3 \\
15\end{array}$ & $\begin{array}{l}24.8 \\
25.7\end{array}$ & $\begin{array}{l}35.1 \\
36.5\end{array}$ & $\begin{array}{l}22-8 \\
27-5\end{array}$ \\
\hline EB-15 & $\begin{array}{l}3558 \\
3720\end{array}$ & $\begin{array}{c}4 \\
80\end{array}$ & $\begin{array}{l}10.5 \\
7.3\end{array}$ & $\begin{array}{l}44.4 \\
13.9\end{array}$ & $\begin{array}{l}63.3 \\
26.5\end{array}$ & $\begin{array}{c}48-5 \\
15\end{array}$ \\
\hline EB-18 & $\begin{array}{l}3505 \\
3855\end{array}$ & $\begin{array}{l}18 \\
1.7\end{array}$ & $\begin{array}{c}5.3 \\
14.1\end{array}$ & $\begin{array}{l}40.3 \\
51.2\end{array}$ & $\begin{array}{l}59.6 \\
72.9\end{array}$ & $\begin{array}{c}43-6 \\
53\end{array}$ \\
\hline
\end{tabular}

Значения удельного сопротивления пласта (Rt) определены по данным индукционного каротажа. Оценка точности значений водонасыщенности, рассчитанных в соответствии с модифицированным уравнением Арчи и стандартным уравнением Арчи, проводилась по результатам тестирования продуктивности нефти из исследованных пластов на бурильных трубах [ 8,9 ]. Сравнение данных (таблица 2) показывает, что значения водонасыщенности, полученные по модифицированному уравнению Арчи, лучше согласуются с результатами испытания скважины, чем значения водонасыщенности, полученные с использованием стандартного уравнения Арчи. 

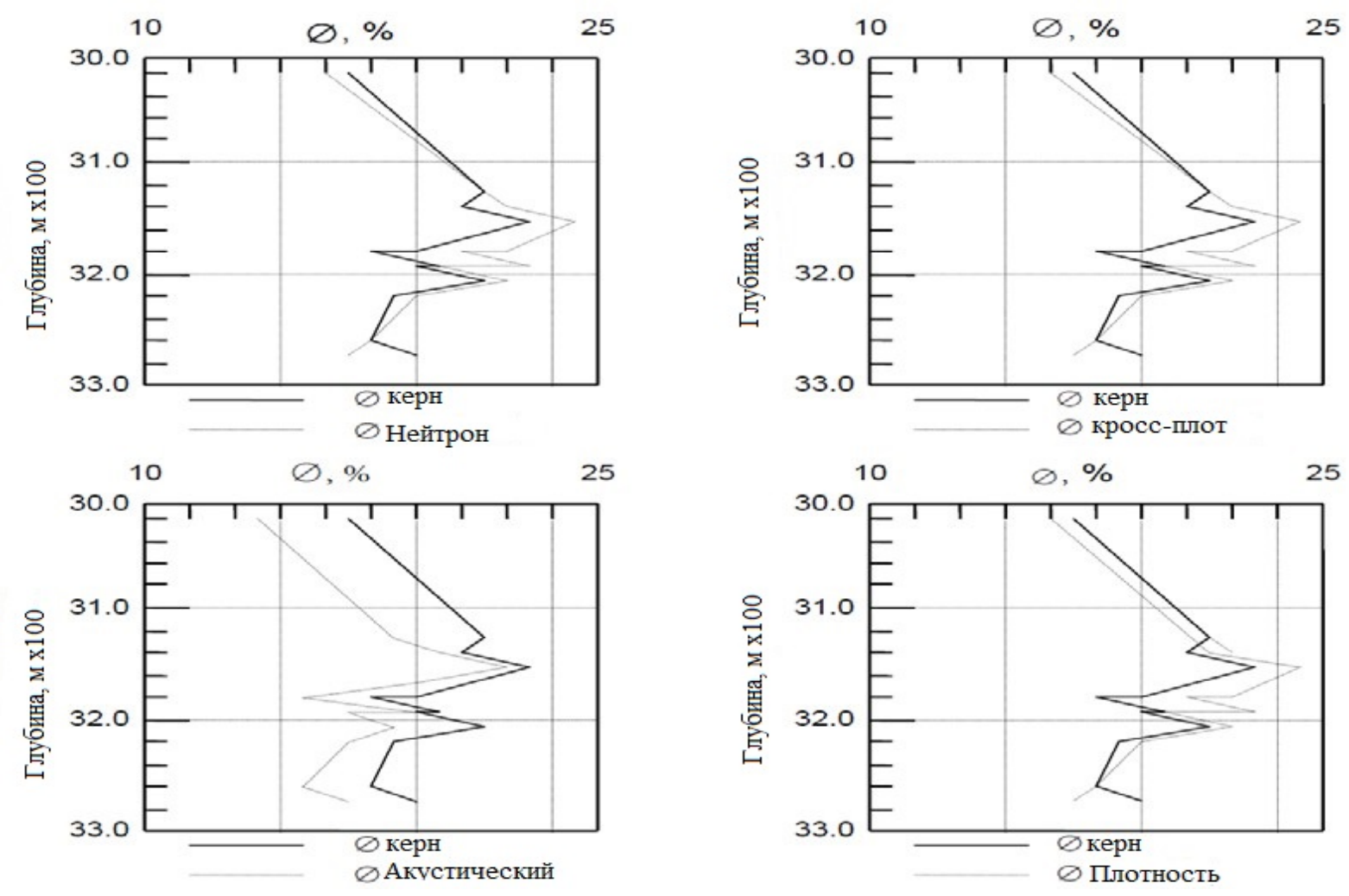

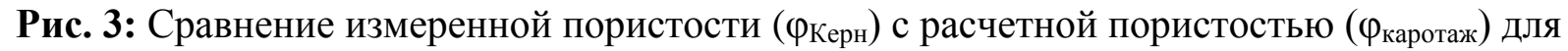
скважины № (ЕВ-56).

\section{Выводы}

На основе статистического анализа корреляционных параметров различных методов каротажа скважин, используемых для расчета эффективной пористости пласта, достоверность более точных результатов повышается за счет использования комплексных методик, состоящих из нейтронного и плотностного каротажей с использованием технологии кросс-плота. Выведена конкретная и модифицированная форма известного уравнения Арчи для определения водонасыщенности пласта .

Данное уравнение позволяет повысить точность определения коэффициентов нефтегазонасыщенности So и Sg. Как известно, точное определение коэффициентов нефте-и газонасыщенности приводит к более точной оценке запасов пласта.

\section{Литература}

[1] Schlumberger log Interpretation Principles. Schlumberger Ltd., 1991.

[2] Al-Obaidi, Sudad Н., and АЛЬ О. С. ХАМИД (1996). “Разработка Методики И Технологии Обработки Данных ГИС И Керна Для Определения Подсчетных Параметров Нефтегазовых Месторождений Ирака : На Прим. Месторождения Вост. Багдад.” OSF Preprints,10.31219/osf.io/f6vka. 
[3] Heslop. Porosity in shaly - sands. SPWLA, 1974.

[4] Robert. Encyclopedia of well logging, 1984.

[5] Al-Obaidi, Sudad Н., and АЛЬ О. С. ХАМИД.(1996). “Определение Глинистости Продуктивных Пластов Месторождений Нефти И Газа Восточного Багдада.” OSF Preprints,10.31219/osf.io/dmw9c.

[6] Poupon et al. Log analysis in formation with complex lithologies. J.Pet Tech., August, 1971.

[7] Al-Obaidi, Sudad Н.(1996). “Разработка Методики И Технологии Обработки Данных ГИС.” OSF Preprints, 10.31219/osf.io/e68us.

[8] Technically Recoverable Shale Oil and Shale Gas Resources: An Assessment of 137 Shale Formations in 41 Countries Outside the United States / U.S. E.I.A. - June 2013.

[9] Al-Obaidi, Sudad H. (1990). "Comparison of Different Logging Techniques for Porosity Determination to Evaluate Water Saturation".Baghdad University, 10.31224/osf.io/fvj9u. 